\title{
The State of Science Education in Post-Independent India: A Synoptic Review and Future Direction
}

\author{
Ramjit Kumar*\& Dr. Smriti Singh \\ Indian Institute of Technology Patna, Bihar India
}

\begin{abstract}
Science is the constitutive feature of the knowledge society. It has changed the way we understand the social and natural world around us. Apart from alleviating us from the traps of ignorance, illiteracy and penury, it challenged the centrality and dominance of metaphysical beliefs in society. The attributes of science like rational, creative, and critical thinking and scientific worldviews are the universal values. These values are essential for the growth of an individual as well as society as a whole. In post independent India, our constitution adopted the goals of establishing society based on the scientific temper, humanism and spirit of inquiry. It is also enshrined in the fundamental duties of the citizen in Article $51 \mathrm{~A}(\mathrm{~h})$ of the constitution that states that it is the duty of the every citizen of the country to inculcate, propagate and further disseminate scientific temper in society. This underlines that science education has distinctive responsibilities to disseminate scientific temper in society. Introducing the idea of science as a process/practice at curriculum level, exposing students to nature of science, and communicating the context of scientific concepts and teaching science through innovative accounts like learning by doing and discoveries in the classroom are some of the important components of pedagogical content knowledge that can be leveraged in the science education program to make science education enjoyable, livable and intrinsic to learning process. It will also bring the issues and context of educational praxis at the center of teaching and learning science education practices.
\end{abstract}

Corresponding author: *Ramjit Kumar is pursuing Ph.D. under the supervision of Dr. Smriti Singh (Associate Professor, Indian Institute of Technology Patna) at Department of Humanities \& Social Sciences, Indian Institute of Technology Patna. He can be contacted at: ramjithss@iitp.ac.in or ramjit.hpsss@ gmail.com

\section{INTRODUCTION}

As a human enterprise, science aims at acquiring objective knowledge of the world. Modern science arose out of late $19^{\text {th }}$ century Enlightenment when society was passing through what Karl Polanyi ${ }^{1}$ has called "the period of great transformation." It was the time words like science, scientific thinking, and scientific worldview came in society along with the ideas of the liberty, justice, equality that increased convulsions. The attributes of science like rational, creative, and critical thinking and scientific worldviews are universal values. These values are essential for the growth of an individual as well as society as a whole.

Zilsel $^{2}$ in an article, the sociological roots of science traced the origin of scientist and defined science as activities, what scientists do? But what scientists do changes over the period of time. To paraphrase what he said what we today call scientist was rather historically first class artisan, plumber etc that with course of time improvised their entrepreneurship. This underlines that methodologically science is more than a dogma and content driven subject that is pre-dominantly taught in classrooms. It is a process, a method, and a philosophy embedded in the social milieu of the society. At the heart of science lies the inquiry system. If content of the science is one side of the coin, another side of the coin is the scientific inquiry.

Science education located in the broader context of knowledge production and politics of society has the distinctive character in society and is different from other subjects. It has a special appeal and invokes the idea that is based on universalism, objectivity and rationalism. Since the aim of science education is not just to make learners aware of the scientific facts and concepts but to make people aware of the benefits of using scientific thinking in personal and public life, dissemination of scientific values is an integral part of the educational process of learning science. In this regard Chunawala \& Natarajan ${ }^{3}$ suggest that it is essential to have the scientific temper of mind as it does help in participating and democratic decision making in both personal and public life. In the context of Indian education system, it is essential, they suggest, developing innovative approach of teaching science to promotes understanding of science as a process that help learners to deal the significant problems of their life. 


\section{SCIENCE EDUCATION IN POST-INDEPENDENT INDIA}

In the post independent India, our constitution adopted the goals of establishing the society based on the scientific temper, humanism and spirit of inquiry. It enshrines in Article $51 \mathrm{~A}(\mathrm{~h})$ of the constitution that it is the fundamental duty of the every citizen of the country to inculcate, propagate and further disseminate the scientific temper in society. In fact, India is the only country in the world that has adopted such obligation in the written constitution.

Science education policy in India is based on the recognition that scientific thinking is the cherished values of human efforts, yearning, and struggles against the culture of fear and limitations. It is as precious as society itself for the advancement of society towards social progressivism to achieve the goals of social, moral and spiritual values and material wellbeing. However, in the recent decades, it has been seen that there is a retreat of public reasoning in the public sphere that has helped in the culmination of and rise of anti-science attitude and religious revivalism in public life (Raina, 2016). This poses a great challenge to the society. In 1981 "A Statement on Scientific Temper," ${ }^{4}$ was endorsed by Nehru Center assuming that scientific inquiry helps people to form and develop their idea and argument based on proof and evidence rather than mundane reasons that would finally negate the prevailing obscurantism and superstitions in the society.

National Council Education Research \& Training (NCERT) Position Paper on science ${ }^{5}$ has recognized that our science textbooks are overloaded with scientific facts. It also mentions that science teaching in India suffers from the problems like- (a). It is lagging behind in achieving enshrined values like humanism, scientific temper and social justice in our constitution. (b) Science education, even at its best, does not encourage inventiveness and creativity. (c) Overpowering examination system is the fundamental problems of science education. Similar conclusions have been also drawn by Aikenhead ${ }^{6}$. According to Aikenhead, students are increasingly disenchanted with the content of school science. School science is full of content which is socially sterile, intellectually boring, and dismissive of student's life. It's no wonder that most students don't able to make meanings out of classroom teaching of science and not able to correlate with what is being taught in the classroom with their personal life. This has proved fatal for the development popularity of science as a subject among students and promoted the myth of science as a brainy and difficult subject. In the similar vein Sarangapani ${ }^{7}$ laments the pathetic condition of the way in which science is being taught in the classrooms. According to her as a country we may take pride in the success of science graduate student abroad but we have failed to take the question of the seriousness of science teaching and learning in the classrooms. Among other problems, she counts is the authoritarian approach of teaching science in India that hardly allows autonomy to learners and teachers. It adheres to absolute and strict interpretation of textbooks in the classrooms ${ }^{8}$. Kumar called it preponderance of the Textbook Culture. Sarangapani ${ }^{7}$ traced out the roots of such outdated monolithic culture of learning in the colonial origin of the education system. According to Mukherjee ${ }^{9}$ in spite of the tremendous socio-political odds, the success of Raman, Saha, and Bose has triggered a sense of pride and jubilance among the Indian people. In 1961, a committee namely Indian parliamentary and scientific committee was formed under the leadership of Late Shri Lal Bahadur Shastri to find out the problems facing science school in Indian school system. The other problems which were taken for serious consideration were finding out the relationship between central and state government policies regarding science education policies and exploring the courses offered in the different schools under different state educational system. In 1964, Indian Education Commission under the chair of Dr. Kothari pointed out that the state of science in India is in pathetic condition and system has failed to reckon with the explosion of knowledge in science. In order to meet this immediate challenge, it was recommended that projects should be conducted to upgrade school curriculum and textbooks. In 1968 , a national policy of education (NPE) ${ }^{10}$ was launched with the aim to connect the development of the nation, citizenship education, and science education. It laid stress on social reconstruction and also on mitigating regional imbalances in the development of educational system. In 1986, $\mathrm{NPE}^{11}$ prioritized the agendas of inclusive education, vocational training, technical and professional education and laid stress on reducing female illiteracy in the country. In this way, educational policy was linked to the spread of scientific literacy and scientific awareness in the society that acted to stimulate the different education subsystem to produce skilled workforce needed the economy. But in this process of production of scientific workforce for the industrial purposes encompasses the darker side. It came as a heavy burden to students at large. Textbooks were overloaded with more and more factual information. Reforms were often done on episodic basis to add more information citing the reason like information explosion. This phenomenon and ideology has been analyzed by famous Canadian science educator Aikenhead ${ }^{6}$ who has called it the pipeline production.

In 1970s, science educators, independent resource groups, and educationists collectively came together to challenge the orthodoxy of Indian school science and pitched in for formulating an approach that contextualizes science education from the learner's centered perspective. Hosangabad Science Teaching Program (HSTP) was one such program that was started in 1972 in Hosangabad district of Madhya Pradesh province of India. The experiences of Hoshangabad Science Teaching Program suggested changing the perspective on science teaching in India. HSTP advocated that country needs a fresh restart to develop a science 
education teaching paradigm and for that science educator, teacher and civil society as a whole have to think outside the box solution. Although closed, HSTP took pride in the fact that innovative concepts like learning by discovery methods, inquiry method, etc. are not only included in the latest policy documents at the national level but also emphasized to practice within the classrooms. Similar efforts of curriculum making were taken in other countries like in the United Kingdom in Nuffield Reforms, and in U.S. National Science Foundation.

In 1975, NCERT in the framework of the curricular objectives has laid down the objectives of education. NCERT defined curriculum as the sum total of all the deliberately planned set of educational experiences provided to the child by the school. Kala \& Ramadas ${ }^{13}$ reviewed these trends in science curriculum reforms research that have occurred worldwide. According to them, Piaget's influences in the domain of science education reforms led to a shift from behaviorism to constructivism and by the 1970s, the major trends in science education research shifted from constructivism to philosophy of science. Philosophy of science, specifically the work of Popper, Kuhn, and Lakatos started to find currency in the domain of science education worldwide. Ideas such as theory-laden observations, nature of scientific inquiry started to impinge in the school curriculum theories and texts. They explained that justification for applying ideas from the philosophy of science to science education can be found in the child as scientist metaphor, which had been subtly present since Piaget. Since child could be considered as a novice scientist, researchers in science education thought that philosophy of science, which attempted to lay down the foundations for science, could similarly be used to interpret children's conceptions of science and provide guidelines for interpreting children's conceptions of science. Confrey ${ }^{14}$ pointed out that philosophy of science allows researchers to critique the underlying inductive conception of science which has permeated science textbooks in the form of the scientific method. However, Kala \& Ramadas ${ }^{13}$ contend that unfortunately in the practices of science education research and curriculum making these developments in domain independent science education research like epistemology studies, cognitive psychology is still to be seen in India.

\section{NEW SCIENCE EDUCATION AND CURRICULUM}

With the upcoming of $21^{\text {st }}$ century the world has witnessed unprecedented socio-economic changes due to explosion in information technology and the process of socio-political and economic integration that necessitated the agendas of reforming the curriculum. The aims of science curriculum reforms across the cultures have been to help students to develop informed and enriching understanding of science and promote science learning as joyous experience that promote critical and creative thinking through various innovative methods like learning by doing, learning by inquiry method, and discovery method.

This is the departure from the old ways of knowing science in schools that only inscribes science teaching by giving instructions that students in the classrooms and school followed to mime and mimic the scientific process. The recognition of the fact that scientific knowledge does not only entail knowledge of products of science but science learning is all about learning processes, cultures and practices of science is important from the educational praxis point of view that emphasizes the bridging the gap between theory and practice. Science learning does include knowing methods, scientific practices of scientists and nature of science. In other words how does scientific knowledge emerge is important to know for student's comprehensive and deeper understanding of scientific knowledge? These episteme values also include questions like what demarcates science from other way of knowing like religion and philosophy. Allchin's ${ }^{12}$ has called it knowing the whole conceptualization of science rather than processed image of science that is currently filters in textbooks. It adopts and hence prescribes the image of science that is reductionist. Adopting the whole conceptualization of science in accordance with the nature of science can be a good starting point to renew the energy that is needed to review of science education curriculum to get benefit from the pedagogical analysis of teaching science. More particularly the idea of teaching of science and about science extracting from philosophy and methodology of science and science studies may work wonder to kill the symptomatic culture of monolithic way of teaching content of science and extrinsic learning of students which is present in today's day education system.

\section{CONCLUSION}

National Curriculum Framework Policy (NCF) ${ }^{15} 2005$ of India recommends teaching science as a process/inquiry and value system. It talks about maintaining the cognitive validity, process validity, historical validity, environmental validity, and ethical validity in science textbooks. But unfortunately, today's science textbook hardly takes cognizance of such issues. It projects the image of science that is empty of the epistemic, cognitive and social values of science. Consequently, as it is the case the overwhelming majority of students ascribe the naive conception of science and teachers continue to structure their science argument in a way that is incommensurate with how scientist proceed to scientific activities, scientific deliberations, and unpack their inquiries into natural phenomena in real life situation. 
The understanding of science as a dynamic enterprise human activities consisting of socio-psycho values that mediates within scientific communities helps learner to situate the scientific knowledge in the real context of social world. The need to apply scientific knowledge in the real life examples like socio-scientific complexities of personal and public issues in society has gained ground. There is increasing importance of pedagogical innovation of teaching science in the classroom that requires (a). teaching nature of science along with the content of science (b). the knowledge of how science is manufactured including the contribution of affective side of human like role socio-psycho effects like creativity and errors. Such a system of pedagogical analysis of teaching science has been enriched by disciplines like History, Philosophy and Sociology of Science (HPSS) that makes complimentary conversation with science education and presents the Nature of Science in brief form to adopt it in science curriculum ${ }^{16}$. Reforms in science curriculum are also necessitated to disseminate scientific temper as the dominant mode of thinking in a society that helps people to base their reasoning on the cause-effect relationship. In fact, scientific thinking that favors the value-system supported by egalitarian, secular, and rational values and promotes the development of the collective conscience of the society based on the spirit of inquiry is accepted on the basis of the right to question and be questioned. It involves knowing the grammar of science so that people can apply it to many aspects of life ranging from ethics to politics to economics.

\section{REFERENCES}

[1] Polanyi, K. (2001). The Great Transformation: The Political and Economic Origins of our Time. Boston: Beacon Press

[2] Zilsel, E. (2000). The Sociological Roots of Science. Social Studies of Science. 30 (6), 935-949.

[3] Chunawala, S. \& Natarajan, C. (2011). A Study of Policies Related to Science Education for Diversity in India. In "Towards Effective Teaching and Meaningful Learning in Mathematics, Science, and Technology", Proceedings of ISTE International Conference on Mathematics, Science and Technology Education, South Africa

[4] A Statement on Scientific Temper (1981). Retrieved 16 June, 2016 from Education Documentation Center website http://el.doccentre.info/eldoc1/setdev/810725mns1B.pdf

[5] NCERT Position Paper on Science 2005. (n.d.). Retrieved from http://www.ncert.nic.in/new_ncert/ncert/rightside/links/focus_group.html

[6] Aikenhead, G. S. (2006). Science Education for Everyday Life: Evidence-based Practice. New York, NY: Teachers College Press.

[7] Sarangapani, P. M. (2014). Three Challenges Facing Indian School Science Education In A. Joy, Science Education: Few Takers for Innovation (pp. 32-35). Mumbai: IKF (IRIS Knowledge Foundation).

[8] Kumar, K. (2004). What is Worth Teaching. New Delhi: Orient Blackswan

[9] Mukherjee, A. (2007, August 16). Science Education in India. Retrieval from http://www.thehindu.com/todays-paper/tp-opinion/science-education-in-india/article1892821.ece

[10] Government of India. National Policy on Education - 1968. Ministry of Education. New Delhi, 1968

[11] Government of India. National Policy on Education - 1986. Ministry of Education. New Delhi. 1986

[12] Allchin, D. (2004). Teaching the Nature of Science: Perspectives \& Resources. Saint Paul, MN: Ships Education Press.

[13] Kala, L. \& Ramadas, J. (2001). History and Philosophy of Science, Cognitive Science and Science Education: Issues at the Interface, Indian Educational Review 37(2), 3-21. Retrieved from http://www.hbcse.tifr.res.in/research-development/vsr/jr-and-lk-history-and-philosophy-ofsciencecompressed.pdf

[14] Confrey, J. (1990). A Review of the Research on Student Conceptions in Mathematics, Science, and Programming Review of Research in Education 16, 3-56. doi:10.3102/0091732X01600100.

[15] National Curriculum Framework 2005, NCERT. (n.d.). Retrieved from http://www.ncert.nic.in/rightside/links/pdf/framework/english/nf2005.pdf

[16] Matthews, M. R. (1994). Science Teaching: The Role of History and Philosophy of Science. Routledge, New York. 